\title{
A DERIVATIONAL APPROACH TO THE FOCUS STRUCTURE
}

\author{
Aritz Irurtzun \\ EHU-U. Basque Country
}

\begin{abstract}
I present a derivational analysis of the construal of the focus structure of the sentence. I propose that the $[+\mathrm{F}]$ feature is an optional formal feature that can be assigned to multiple tokens of the numeration. Hence, the focus structure is derived via Merge (creation of a set) in a strictly compositional way. I argue that with the adoption of this theory we can circumvent many of the empirical and theoretical shortcomings of previous Nuclear Stress Rule-based approaches, and, furthermore, that it allows us to account for split focus constructions (answers to multiple Wh questions) in a natural way.
\end{abstract}

\section{1-Introduction ${ }^{1}$}

In this paper I present a new theory of the composition of the Focus Structure (henceforth, F-structure) based in a dynamic construal of syntactic phrases. As will be shown, this theory allows building up the F-Structure of a sentence directly in the narrow syntactic component, and hence, it provides the structural description for the interpretive rules that apply to the F-Structure at the interfaces (accentuation, phonological phrasing, association with operators etc.) without positing look ahead or intermodular operations. I will also show that previous theories of F-Structure based in the Nuclear Stress Rule (henceforth NSR), and Focus Projection (e.g. Cinque (1993), Reihnart (1995, 2006), Selkirk (1995), Neeleman \& Reinhart (1998), Zubizarreta (1998) or Arregi (2003)), have strong

\footnotetext{
${ }^{1}$ I want to thank Ž. Bošković, G. Elordieta, A. Elordieta, R. Etxepare, J. Ormazabal, L. Selkirk, J. Uriagereka, M. Uribe-Etxeberria and two anonymous reviewers of CJL/RCL for helpful comments on the ideas presented here. Special thanks are due to my fellows M. Duguine, U. Etxeberria and A. J. Gallego, for their patience and helpful discussion on this work. Usual disclaimers apply. This research was supported by the grant BFF200204238-C02-01 of MCYT \& FEDER and a research grant by the Basque Government.
} 
empirical and conceptual problems that don't arise with the derivational approach to the FStructure construal proposed here.

This article has the following structure: in section 2 I give an overview of the nuclear stress phenomena and the NSR. Section 3 is a review of the main features of the mainstream NSR-based theories of F-Structure and in section 4, I give empirical as well as conceptual evidence that show the inadequacy of NSR-based theories. Next, in section 5, I make my proposal of F-Structure construal in a derivational way and in the last section I give some empirical evidence that shows how the adoption of the proposal in this paper allows us to account for split F-Structures, problematic data for previous approaches. A seventh section with the general conclusions closes the article.

\section{2-The Nuclear Stress Phenomena and Nuclear Stress Rule}

The nuclear stress phenomenon can be illustrated with data like (1a-b) for English and Basque respectively. In both languages, in out-of-the-blue sentences, the main stress of the sentence (called the nuclear stress) surfaces in the element 'Judea'2:

(1a) ENGLISH: Jesus preached to the people of Judea.

(1b) BASQUE: Jesusek Judeako jendeari predikatu zion. Jesus Judea-of people-to preached AUX "Jesus preached to the people of Judea"

In order to account for the differences in the position of the nuclear stress in different languages, Halle \& Vergnaud (1987) proposed a parametrically variable NSR and posited that different parameter settings of the rule derive the differences in surface position of the nuclear stress in different languages.

\footnotetext{
${ }^{2}$ I use boldface to mark nuclear stress.
} 
However, Cinque (1993) proposes to dispense with the parametrically variable NSR, and to analyze the data as a direct mapping between syntax and PF whereby the syntactic bracketing is mapped directly into metrical bracketing. The rule Cinque (1993) proposes can be summarized as follows:

(2)

(a) Interpret boundaries of syntactic constituents as metrical boundaries.

(b) Locate the heads of line $N$ constituents on line $N+1$.

(c) Each rule applies to a maximal string containing no internal boundaries.

(d) An asterisk on line $N$ must correspond to an asterisk on line $N+1$.

Thus, according to Cinque's NSR, there is a tight connection between syntactic phrases and metrical brackets, and the more embedded an element is in the syntactic component, the more embedded it will get at the metrical grid:

(3) Jesus preached to the people of Judea

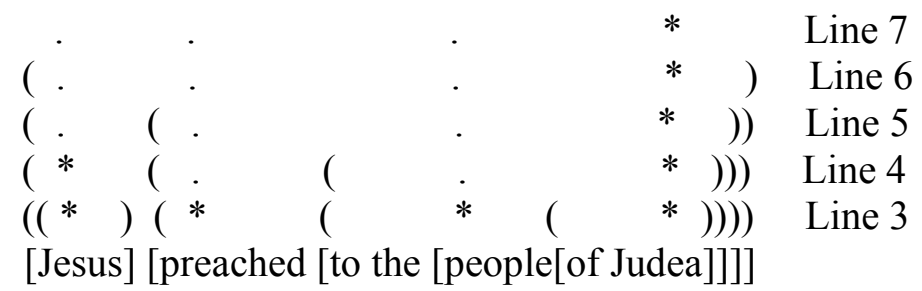

The conclusion to be derived from Cinque's proposal is that the surface differences in nuclear stress placement observed in different languages can be derived from a basic difference among them; namely, the head parameter (cf. Cinque (1993, p. 245)). Thus, there will be no need to postulate different parameter settings of the NSR for different languages; the parametric difference is already built in the head parameter: 
(4)
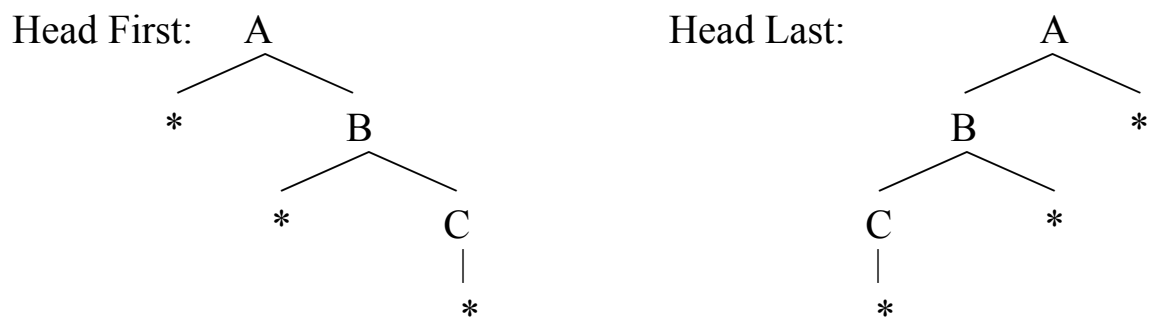

Thus, it is easily explainable the fact that in both languages, in out-of-the-blue contexts, it is the same element getting the nuclear stress; the most embedded 'Judea'. However, the nuclear stress is not a static phenomenon, and it surfaces in different positions in contexts that are not out-of-the-blue. The observation is that in these 'contextualized' environments the nuclear stress always falls on the focal XP, be it the syntactic object, the subject, or any other element. Nuclear stress placement is thus strictly correlated with different F-Structures: when focus is on the direct object, the accent is on the direct object itself. Likewise when the VP is focused or in an out-of-the-blue environment where the whole sentence is focused ( $c f .(5))$; in all these cases nuclear stress falls on the object. On the other hand, focus on the verb correlates with nuclear stress on the verb (cf. (6)), and focus on the subject correlates with stress assignment to the subject (cf. (7)):

(5) $\left[\text { John }\left[\text { boiled }[\text { water }]_{\mathrm{F}}\right]_{\mathrm{F}}\right]_{\mathrm{F}}$.

(6) John $[\text { boiled }]_{\mathrm{F}}$ water.

(7) $[\text { John }]_{F}$ boiled water.

Departing from the observation of this correlation between nuclear stress placement and the possible F-Structures of a sentence, a very successful theory of F-Structure has been developed in the last decade. In the next section I review the main points of that theory. 


\section{3-Theories of F-Structure based on the Nuclear Stress Rule}

Many scholars have taken the fact that in many languages focus bears the nuclear stress to be the effect of a representational legibility condition on derivations that reclaims focus to have the nuclear stress at PF. Thus, adopting the original ideas of Cinque (1993) many proposals and refinements have been made in different ways in Reinhart (1995, 2006), Neeleman \& Reinhart (1998), Selkirk (1995), Zubizarreta (1998), Szendröi (2001), Arregi (2003), Elordieta (2001), Zubizarreta \& Vergnaud (2000), and Ishihara (2000) among others. According to these approaches, the variation observed in the sentences of (8a-g) would be an instance of 'focus projection', since it is posited that the element that bears the nuclear stress will be able to 'project' its focal status to higher nodes that dominate it:

(8a) Jesus preached to the people of $[\text { Judea }]_{\mathrm{F}}$

(8b) Jesus preached to the people [of Judea $]_{\mathrm{F}}$

(8c) Jesus preached to the [people of Judea $]_{\mathrm{F}}$

(8d) Jesus preached to [the people of Judea $]_{\mathrm{F}}$

(8e) Jesus preached [to the people of Judea $]_{\mathrm{F}}$

(8f) Jesus [preached to the people of Judea $]_{F}$

$(8 \mathrm{~g})[\text { Jesus preached to the people of Judea }]_{\mathrm{F}}$

Recall then that the focus projection is just a natural conclusion of the adoption of this view where the focal XP is interpreted as such depending on where the nuclear stress falls. Thus, according to this view, having the nuclear stress in the most deeply embedded element in (8), this stress placement will be able to convey many different F-Structures (up to the whole sentence). The main consequence of the adoption of this idea is that, a sentence won't have an 'actual focus' but 'a set of possible foci', the set of nodes that an 
actual nuclear stress placement can mark as focused. This idea is explicitly stated, for instance, in Reinhart (2006), p. 158 $8^{3}$ :

(9) The focus set: The focus set of a derivation D includes all and only the constituents that contain the main stress of D.

This focus rule predicts the basic facts of focus projection of the sentences in (5) and (8) and allows the nuclear stress on the object to mark as focused the direct object itself, the VP, or the whole clause. According to Reinhart $(1995,2006)$ this will be the default case, where NSR assigns nuclear stress to the most embedded position. However, this strategy won't serve to mark focus on some elements like the subject or the verb, since, clearly, they don't contain the nuclear stressed element (providing that, as said before, by default, the NSR assigned nuclear stress to the object). Thus, according to Reinhart (1995, 2006), in order to mark focus on an phrase that cannot be marked by the projection from the object (i.e., a phrase not on the original focus set), some marked strategies will be employed: in English-like languages where focus doesn't affect the word order, a deaccenting rule will deaccent the object and a marked stress rule will assign nuclear stress to whichever element has to be interpreted as focused $(10)^{4}$ :

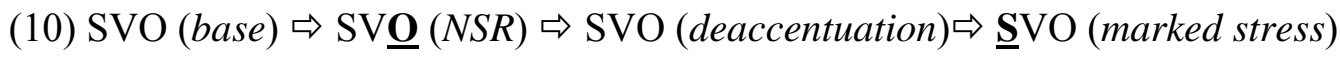

On the other hand, in languages like Dutch or Basque, where the basic order of constituents is affected by focus, it is posited that the elements that are the most embedded are scrambled higher up in the structure, leaving whichever element has to be interpreted as focus in the most embedded position (11):

\footnotetext{
${ }^{3}$ Selkirk (1995) proposes an analogous rule of focus projection from heads to phrases that has also been very influential (cf. i.a. Schwarzschild (1999)). The main difference between the proposals in Selkirk (1995) and Reinhart $(1995,2006)$ is that for the former the PF rule of projection applies optionally and for the latter it applies automatically (creating focus sets).

${ }^{4}$ Here I mark nuclear stress with boldface and with an underline for clarity.
} 
(11) SOV (base) $\Rightarrow$ OSV (scrambling of O) $\Rightarrow$ O $\underline{S V}$ (NSR)

It is these two types of strategy that will provide the intended focus-nuclear stress correlation at PF (cf. Reinhart (2006) for the specificities of these operations and section 4.2 for discussion of Basque data).

There remains a last problem though: contrary to fact, according to the focus rule in (9) nuclear stress placement on a subject should also be able to denote sentence-focus; after all the CP does contain the nuclear stress and after the marked operation the focus set is $\{$ Subject, CP . However, according to Reinhart $(1995,2006)$ that is not an available option, since that would be antieconomical. In fact, the sentence-focus interpretation could have been obtained via projection from the nuclear stress of the object in the base configuration and without having to incur into marked operations (as we saw before). According to Reinhart $(1995,2006)$ then, it is more economical to interpret sentence focus from the projection of the NSR applied to the object by default, than interpreting it as the outcome of accenting the object first, deaccenting it, and applying the 'marked' stress rule to the subject to interpret sentence-focus from the projection from the subject. An economy principle will prevent then from that computation. And economy is computed by comparison of both possibilities for interpreting focus on the whole clause (what Reinhart (2006) calls a 'reference-set computation').

Taken the basic idea of NSR and F-Structure, there has developed a very productive program of research refining the theory as well as applying it to previously unstudied languages. In this work I will call this program of research the 'NSR-based theories of FStructure', given that in all these proposals there is no focus phrase per se, but focus is computed on phrases that contain the nuclear stress (cf. section 4.3 for discussion and clarifications on this issue). The gist of all these approaches is that there is a legibility 
condition on derivations reclaiming focus to have nuclear stress at PF. According to this theory, then, the nuclear stress placement is the trigger of F-Structure in PF and hence, the F-Structure of a sentence is ambiguous (since the accented element can denote, via projection, a set of different F-Structures). In the following section I provide empirical and conceptual arguments that show that this type of theory cannot be maintained.

\section{4-Evidence Against the NSR-based Theories of F-Structure}

In this section I present both empirical and conceptual arguments against the NSRbased theories of F-Structure and, as a corollary, I claim for the need of a new type of explanation for the nature of focus (see section 5 for such a proposal).

I will start from the empirical evidence (sections 4.1 and 4.2 ) to go next (section 4.3) to the more conceptual arguments that show that a NSR-based theory of the F-Structure cannot be maintained.

\section{1-Phonological evidence against the NSR-based theories of F-Structure}

\subsection{1-Categorically Different Nuclear Pitch-accents}

According to the NSR-based theories, there is a bare output condition that reclaims focused material to bear the nuclear stress and this stress, via projection, is able to mark as focused any phrase that contains the word with the nuclear stress. Then, as explained in section 3, economy conditions will dictate what the actual focus possibilities are, and the actual focus will be chosen at the discourse level. In this regard, it seems to me that the nuclear accents that these theories are assigning are taken to be some sort of [+Accented] diacritics, i.e., suprasegmental features with no internal tune-structure nor autosegmental linearization. However, at least since Liberman (1975) and Pierrehumbert's (1980) seminal 
works in English intonation, pitch-accents with different tune-structures have been described expressing different meanings (see, among others, Pierrehumbert \& Hirschberg (1990), Ladd (1996)). And in fact, in many of the best studied languages in the Autosegmental-Metrical framework of intonational phonology we can observe systematic differences between the nuclear accents used to convey narrow focus and those used to convey broad focus. Crucially, the different tune-composition and alignment of a pitchaccent is a categorical distinctive feature of the accent so that a $\mathrm{H}^{*}$, a $\mathrm{L}+\mathrm{H}^{*}$ and a $\mathrm{L}^{*}+\mathrm{H}$ accents are different phonological entities stored as such in the 'intonational lexicon' of a given language. Among the languages or varieties that make use of categorically different pitch-accents to denote broad and narrow foci we can find the following ones:

-English (cf. Selkirk (2002a)): Broad Focus H*, Narrow Focus L+H*.

-Bengali (cf. Hayes \& Lahiri (1991)): Broad Focus H*/L+H*, Narrow Focus: L* $\mathrm{H}_{\mathrm{P}} \mathrm{L}_{\mathrm{I}}$.

-Italian (cf. D’Imperio (2002)): Broad Focus H+L*, Narrow Focus L+H*.

-European Portuguese (variety of Lisbon) (cf. Frota (2000)): Broad Focus H+L*, Narrow Focus $\mathrm{H}^{*}+\mathrm{L}$.

-Greek (cf. Baltazani (2002)): Broad Focus $\mathrm{H}^{*} / \mathrm{H}^{*}+\mathrm{L}$, Narrow Focus L+H*.

-Errenteria Basque (cf. Irurtzun (2003)): Broad Focus $\mathrm{H}^{*}$, Narrow Focus $\mathrm{H}^{*+} \mathrm{L}$.

Hence, if we pay attention to these data, a stressed direct object in a SVO configuration like (13) (for a head-first language) doesn't convey an ambiguous FStructure. That is, no single accent can mark broad and narrow foci. Then, the systematic 
distinction of categorically different pitch accents for narrow and broad foci shows that there can be no focus projection:

$(13)^{5}$ :

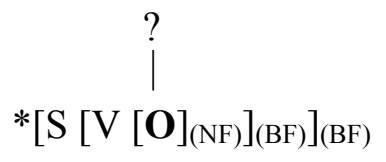

Clearly, the correlation between type of accent and type of focus requires that the FStructure has to be set derivationally before the phonological component assigns a determinate accent to the metrical structure built up from the syntactic structure ${ }^{6}$. The key idea here is that the purported F-Structure ambiguity is not such an ambiguity; and without that ambiguity, the potential focus projection and the focus set are unsustainable. Hence, it cannot be the case that the F-Structure is computed after all syntactic, semantic, and phonological computations are over.

\subsection{2-Focus-induced phonological phrasing}

Similar evidence against the NSR-based theories of F-Structure can be extracted from the fact that some languages use a determined phonological phrasing to convey focus. In many languages, a systematic correlation between focusing and phonological phrasing can be observed, which, whatever the analysis for the prosodic phrasing facts, clearly vindicates against the premises of the NSR-based theories of F-Structure. Among others, languages in which there is a correlation between the F-Structure and a phonological phrase alignment are:

\footnotetext{
${ }^{5}$ The subscripts 'NF' and 'BF' stand for 'Narrow Focus' and 'Broad Focus' respectively.

${ }^{6}$ Even if I won't endorse here the NSR-based theory of F-Structure, I will still assume the cinquean NSR, since this is the most comprehensive mapping between syntactic structure and phonological metrical grid (see (39) in section 5 for the modification of the NSR that I propose).
} 
-Left Alignment: Tokyo Japanese (cf. Pierrehumbert \& Beckman (1988), Bengali (cf.

Hayes \& Lahiri (1991), Selkirk (2006)), Korean (cf. Jun (1993)),

Lekeitio Basque (cf. Elordieta (2006))...

-Right Alignment: Chicheŵa (cf. Kannerva (1990), Truckenbrodt (1995, 1999)), English (cf. Selkirk (2000), Brazilian Portuguese (cf. Sandalo \& Truckenbrodt (2001)) ...

This evidence shows again that it cannot be the case that the F-Structure of a sentence is undetermined or ambiguous, nor that the 'actual focus' is chosen from a set of 'possible foci' at the discourse level (once all syntactic, semantic, and phonological computations are over). If the phonological phrasing of the sentence is affected by the nature of the actual focus, then the actual focus has to be set derivationally before the phonological component deals with prosodic phrasing ${ }^{7}$.

As a matter of preliminary conclusion, I just want to emphasize that sentences don't have ambiguous F-Structures, as the intonational evidence shows. This means that the FStructure has to be set at some point in the derivation from the numeration to PF.

\subsection{3-No accent conveying focus}

As we saw, the main premise of NSR-based theories of F-Structure is the purported necessary correlation between focus and nuclear stress at PF. However, it has been discussed in the literature that some languages and varieties make use of no accentual cue

\footnotetext{
${ }^{7} \mathrm{I}$ am agnostic here as to what is the correct characterization of the phrasing itself, be it rule-based or harmonic candidate computation. The fact is that both types of architecture of the grammar require unambiguous F-Structures to align them with the relevant phonological phrase.
} 
to mark focus. Among them we can find Hyxkariana (cf. Derbyshire (1985)), Guyanese English Creole (cf. Bickerton (1993)), French (cf. Féry (2001)), Wolof (cf. Rialland \& Robert (2001)) and some constructions of Russian (cf. King (1995)) and Lekeitio Basque (cf. Elordieta (2006)).

Thus, a different focalization mechanism would have to be posited for these languages to set the F-Structure. Recall here that the issue is not about a parametrically different realization of the F-Structure in different languages (something that in fact, any look at crosslinguistic data reveals). The issue is that if the NSR-based theories of FStructure were right in postulating a legibility condition (a Bare Output Condition) that reclaimed focused phrases to bear the nuclear stress, these languages would have to have a different architecture of the grammar with different Bare Output Conditions from, for instance, those of English speakers'. No need to argue that this view is incoherent given minimalist assumptions, since interface conditions on representations cannot be subject to parametric variation. In fact, by assumption, "conditions on representations [...] hold only at the interface, and are motivated by properties of the interface, perhaps properly understood as modes of interpretation by performance systems" (Chomsky (1995b), p. 170)). And, of course, performance systems are the same for Hyxkariana speakers and Dutch speakers, and, likewise, they are also the same for potential Hyxkariana-Dutch bilinguals ${ }^{8}$.

\footnotetext{
${ }^{8}$ It could be argued that the purported legibility condition is more abstract than the explicit proposal of the NSR-based theories of F-Structure (I thank J. Ormazabal, I. Laka and an anonymous reviewer for raising this point to me). However, from a minimalist point of view, legibility conditions are Bare Output Conditions without whom no computation can proceed (like, the need for linear order of terminals or the avoidance of vacuous quantification). Hence, they are not subject to parametric variation (see below). Furthermore, the postulation of such an unspecified legibility condition to account for the variation in the surface effects of focus across languages would lack sufficient empirical motivation.
} 
After having reviewed some of the phonological evidence against the premises under the NSR-based theories of F-Structure, now I will review some of the syntactic evidence that shows that this type of theory of the F-Structure cannot be maintained. The discussion will be based on Basque data, a discourse configurational language where the focal XP appears left adjacent to the inflected verb ${ }^{9}$. Here, I will just discuss some relevant data in a very basic way and with the purpose of showing the problems that arise with the adoption of NSR-based theories of the F-Structure.

\section{2-Syntactic evidence against the NSR-based theories of F-Structure}

The basic word order of Basque is SOV (that is the order of constituents in an outof-the-blue sentence like (15a)).

(15a) [Jonek mahaia hautsi du $]_{\mathrm{F}}$.

Jon table broke AUX

'[Jon broke the table $]_{\mathrm{F}}$ '

However, it is a well known fact that (Central-Western) Basque shows mandatory Focus-Verb adjacency. Thus, sentence (15b) is ungrammatical because the focalized subject is not left-adjacent to the verb, whereas their variants in (15c-d) are grammatical precisely because of this configuration:

$(15 b) *[\text { Jonek }]_{\mathrm{F}}$ mahaia hautsi du.

(15c) Mahaia $[\text { Jonek }]_{\mathrm{F}}$ hautsi du.

(15d) $[\text { Jonek }]_{\mathrm{F}}$ hautsi du mahaia.

\footnotetext{
${ }^{9}$ See Kiss (1995) on discourse-configurationality and Ortiz de Urbina $(1986,1995)$ and Hualde \& Ortiz de Urbina (2003) for discussion on Basque data.
} 
From the Principles and Parameters theory, the mainstream way of looking at these data is by the postulation of a strong $[+\mathrm{F}]$ feature that has to be checked against the verb in a Spec-Head configuration in a functional projection of the left periphery of the clause (traditionally taken to be $\mathrm{CP}$ or FocP). However, under the NSR-based theories of FStructure the movements that take place in these constructions are not instances of movements of focal material (clearly, that would require the syntactic identification of the F-Structure, and then, it would deny their assumption that the actual focus is chosen from a focus set at the discourse level). Rather, they are taken to be movements of nonfocal material in order to fulfill the legibility condition on derivations that reclaims focused elements to have nuclear stress at PF. Thus, according to this view, when a nonfocal element happens to be in the most embedded position in the clause, a 'nuclear stress avoiding' movement of this nonfocal element takes place so that the element to be identified as focused becomes the most embedded element in the structure, and thus, it receives the nuclear stress (as we saw in section 3$)^{10}$. These types of movements are the 'scrambling' mechanisms proposed in Elordieta (2001) or the left and right dislocations proposed in Arregi (2003). As an illustration, a representation of the structure of the sentence (15c) under Arregi's (2003) proposal is below ${ }^{11}$ :

\footnotetext{
${ }^{10}$ See next section for a criticism of this purported dual (syntactic/discursive) nature of focus.

${ }^{11}$ Elordieta (2001) presents a mixed left peripheric/NSR-based analysis of Basque. Here, for the ease of exposition I will just comment on the 'pure' NSR-based analysis in Arregi (2003).
} 
(16)

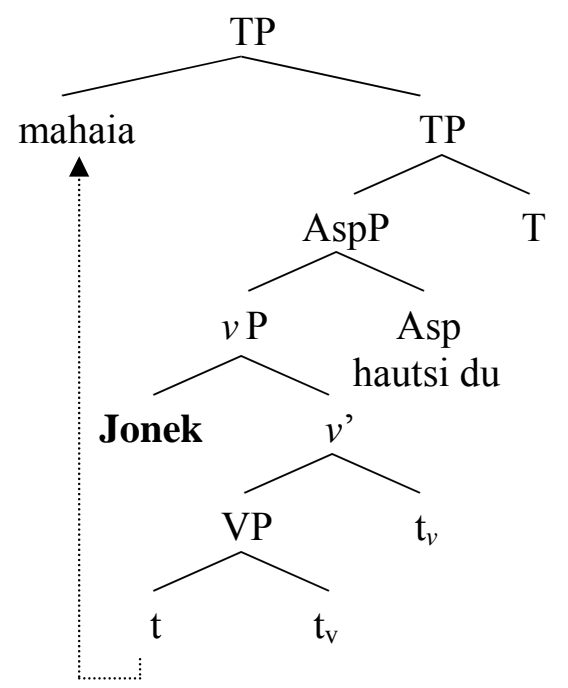

In (16), movement of the object 'mahaia' over the subject 'Jonek' renders the latter in the most deeply embedded position and, thus, it gets interpreted as focus. Note then that according to this proposal, the PF Focus-Verb adjacency is just accidental; a byproduct of the 'nuclear stress avoiding movements' of the nonfocal elements. After the movement of the object it just happens that the focal 'Jonek' is left-adjacent to the verb, but there is no intrinsic reason for this adjacency to hold (in other words, there is no special relation between the focal XP and the verb).

However, I believe that this type of proposal is misguided. Besides the reasons that I will discuss in section 4.3 , this proposal makes too strong predictions regarding (i) the necessary deepmost embedding of the focal XP, and (ii) the accidental adjacency between focus and verb.

In fact, these predictions are not borne out. To begin with, observe the structure in (17) where the object of the embedded clause is the focus.

(17) $[\text { Jon }]_{\mathrm{F}}$ pentsatzen dut [CP ikusi zuela Mirenek] Jon think AUX seen AUX Miren

'I think Miren saw [Jon $]_{\mathrm{F}}$ ' 
Any NSR-based theory of the F-Structure that wanted to maintain that the object of the embedded sentence 'Jon' is the most deeply embedded element on the whole clause would have to posit a number of non-standard rightward movements of the nonfocal elements in order to get that configuration and the leftmost position of the focal XP. However, even with that move, the data of (17) show that the focus-verb adjacency is not a mere accident, given that the subject and verb are inverted on the embedded sentence (this suggests a leftward successive cyclic movement of focus accompanied by the verb) $)^{12}$.

The same picture arises with the clausal pied-piping phenomena. Observe the construction in (18):

(18) $\left[\right.$ Bihar $[\text { Jon }]_{\mathrm{F}}$ etorriko dela $]$ esan dio Aitorrek Mireni. tomorrow Jon come AUX-C ${ }^{0}$ said AUX Aitor Miren-to 'Aitor told Miren that $[\mathrm{Jon}]_{\mathrm{F}}$ will come tomorrow'

Again, a number of non-standard movements would have to be posited in order to have the focal 'Jon' at the left and at the same time in the most embedded position of the entire clause. Besides that, the embedded clause shows left-adjacency to the main clause verb, which cannot be obtained without a movement of the verb. To me, these patterns of focus-verb adjacency in (15) and (16) are clearly reminiscent of the patterns displayed by Wh movements (long distance movements (cf. 17), and clausal pied-piping in (cf. 18)). Hence, it seems to me that an analysis based on movements to the left periphery of the clause might be more adequate to treat these data.

\footnotetext{
${ }^{12}$ Arregi (2003) discuses similar data without the subject-verb inversion of the embedded sentence and proposes that the focus gets extracted from its clause and adjoined to the matrix $v \mathrm{P}$. Then, the embedded $\mathrm{CP}$ is right dislocated. To me the data of Arregi (2003) are not that grammatical (cf. as well Laka \& Uriagereka (1987) and Ortiz de Urbina (1995)). In any event, in order to explain the position of the verb in (15) another ad hoc movement would have to be posited, which reveals that focus-verb adjacency cannot be just accidental.
} 
The goal of this work is to provide a minimalist theory of the F-Structure construction, and I won't enter here on an analysis of the left periphery in Basque (but $c f$. Irurtzun (2006) for an analysis of the syntax-semantics interface that builds on Ortiz de Urbina’s $(1989,1995)$ work).

In a nutshell, the main conclusion that should be derived from this discussion is that the premise that nuclear stress is assigned to the most embedded position in the clause and that focus is computed over nuclear-stressed phrases cannot be maintained. The word order changes induced by focus cannot be explained by standard movements of nonfocal elements. Rather, they require making reference to the actual focal XP of a clause, which denies the possibility of ambiguous F-Structures or focal projections.

In the next section I explain some of the conceptual anomalies that arise with the adoption of a NSR-based theory of the F-Structure.

\section{3-Minimalist Program and the Architecture of the Grammar:}

I will now address the core conceptual problems that a NSR-based theory of FStructure raises. To begin with, I want to make explicit the lack of explicitness of these approaches: as explained before, their main premises are based on a purported interface condition that requires focus to have the nuclear stress at PF. This argumentation is paradoxical in its conception of the F-Structure since, on the one hand there is the assumption that the F-Structure is somehow there at the beginning of the derivation, and on the other hand it is claimed that PF is the responsible of delimiting it given the NSR and FProjection. Basically, the question is the following one: if there is no F-Structure from the beginning, then ceteris paribus the NSR should invariably assign nuclear stress to the most deeply embedded element, and there would be no reasons for scrambling movements nor 
marked stress assignments. On the other hand, if the F-Structure is there from the beginning, then, there is no need to postulate ambiguities, focus sets, nor focus projections. As I will discuss presently, the problem is that the argumentation of NSR-based theories of the F-Structure is necessarily circular: the focal XP of a sentence will be inferred from the phrase that gets the nuclear stress, but on the other hand, the position of the nuclear stress will depend on what the actual focus is. Clearly, this type of argumentation is circular.

Furthermore, the paradox of circularity of argumentation that I alluded to brings another issue concerning the identification of the focal XP. For concreteness, the question is the following one: if there is a $[+\mathrm{F}]$ feature from the beginning, how is it assigned? If there is not, how is focus interpreted? Within the framework of NSR-based theories of FStructure two main types of proposals have been made for the issue of the $[+\mathrm{F}]$ feature:

(i) $[+F]$ featureless theories (cf. i.a. Szendröi (2001), Reinhart (2006))

(ii) one $[+\mathrm{F}]$ featured theories (cf. i.a. Zubizarreta (1998)).

I believe both of them to be wrong for the reasons exposed below.

\subsection{1: Theories that don't postulate any $[+F]$ feature}

The syntactic architecture proposed in theories that don't postulate any $[+\mathrm{F}]$ feature (e.g., Szendröi (2001), Reinhart (2006)) cannot be operative. Let me explain this: if in those theories it is the nuclear accent placement what will trigger the setting of a focus set, the computational system will not be able to 'read' an element as focused or unfocused since, assuming Bare Phrase Structure (cf. Chomsky (1995a)), lexical items are just bundles of features, and nothing distinguishes a 'discursively' focused XP from an unfocused XP if there's no feature difference among them. To put it in a plain way: given the core 
minimalist assumptions, if there is no feature difference, there is no difference. So, according to $[+\mathrm{F}]$ featureless theories, the DP subjects in (19b) and (20b) are just identical.

(19a) Who likes cod?

(19b) Ibon likes cod.

(20a) What does Ibon like?

(20b) Ibon likes cod.

The implications of this move are clear: if there is no feature difference among the subjects of (19b) and (20b), there should be no distinction for computational system between them, and thus, they should behave in the very same way. Likewise, lacking any feature distinction, in an everything in situ language like English the phonological component shouldn't be able to 'know' where to assign the nuclear stress or how to phrase the structure, since such a notion as 'discursively focused' cannot be available during the computation. Actually, as I said before, if there is no unambiguous F-Structure set at PF, we should have invariably nuclear stress on the most deeply embedded element, and in a SOV sentence of English the focus set should always be $\{\mathrm{CP}, \mathrm{VP}, \mathrm{Obj}\}$. Thus, there should be no reason to apply the marked stress rules or movement operations that NSR-based theories of the F-Structure postulate. Actually, the proposal of marked operations to focalize other elements requires syntactically set F-Structures, which requires $[+F]$ features, which denies that focus is just computed over the XPs that contain the element that has the nuclear stress at PF. 


\subsection{2: Theories that assume one $[+F]$ feature}

F-Structure theories that assume the early assignment of just one $[+\mathrm{F}]$ feature and its possible percolation or projection have a drawback since in there is no inherent reason for the $\mathrm{N}$ in the following configuration (21),

(21)

$$
\mathrm{N}_{[+\mathrm{F}]}
$$

that will form an NP,

$$
\left.\right|_{\mathrm{N}_{[+\mathrm{F}]}} ^{\mathrm{NP}_{[+\mathrm{F}] \text { (projection) }}}
$$

that will form the DP Object,

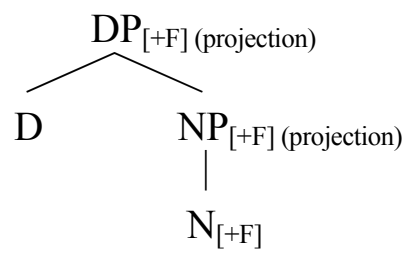

that will be embedded in a VP,<smiles>[Y17]C([2H])[Pb](C)[PH+](C)N</smiles> 
that will form a $v \mathrm{P}$,

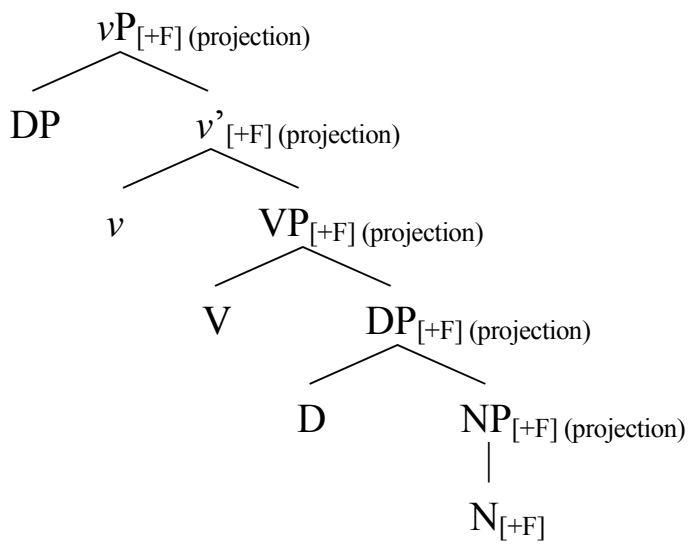

that will end up forming a $\mathrm{CP}$,

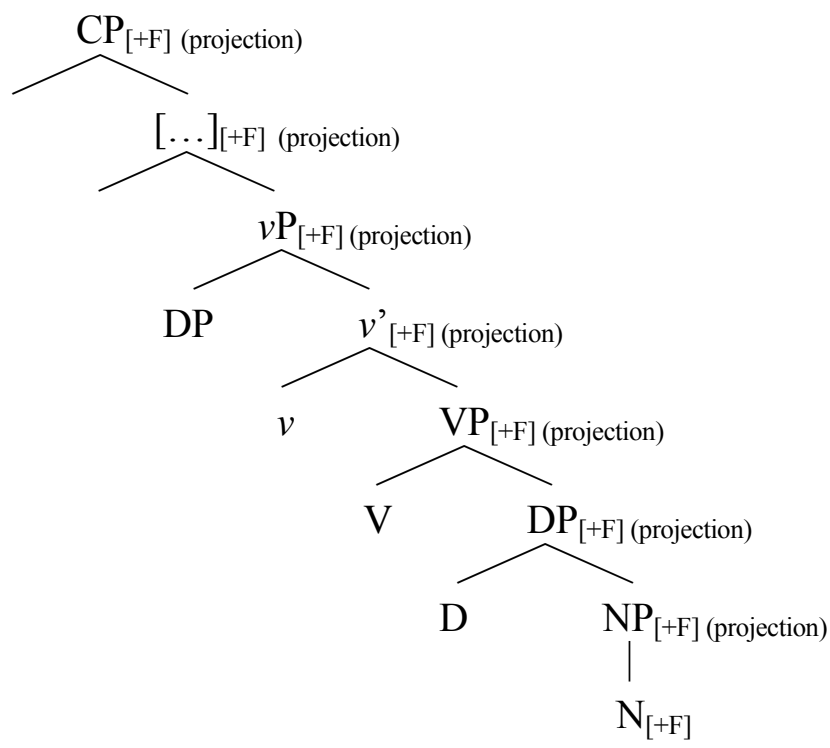

to receive the $[+\mathrm{F}]$ feature when we will end up in a derivation with a sentence-whole focus (an out-of-the-blue sentence). To have this $\mathrm{N}$ marked as $[+\mathrm{F}]$ and it to project its feature in order to get a CP focus is just a theory-convenient stipulation. Note here that this wouldn't be a problem for a 'blind' or derivational theory, but, as explained before, the NSR-based theory has a teleological flavor; all the system works towards the correct focalization of an element by the satisfaction of a PF legibility constraint. Thus, if the element that ultimately 
has to be focused is not on the most embedded position, some marked operations are posited (cf. section 3).

Given this, we can conclude that 'one $[+\mathrm{F}]$ featured theories' that postulate the early insertion of this feature are unable to explain their ad hoc axiom of feature assignment.

On the other hand, there are theories of late insertion of one $[+\mathrm{F}]$ feature: again, a theoretical puzzle arises with these theories; if the $[+\mathrm{F}]$ feature is assigned to a built up XP, and hence, the $[+\mathrm{F}]$ feature was not in the original numeration, we incur in a violation of one of the most basic assumptions of the minimalist program; the Inclusiveness Condition:

"A 'perfect language' should meet the condition of inclusiveness: any structure formed by the computation (in particular, $\pi$ and $\lambda$ ) is constituted of elements already present in the lexical items selected for $N$; no new objects are added in the course of computation apart than rearrangements of lexical properties...”.

[Chomsky (1995b), p. 228]

If we want to maintain the Inclusiveness Condition, then we have to conclude that adding the $[+F]$ feature to a complex XP clearly violates it ${ }^{13}$.

Recall as well that the notion of focus set is crucial to this theory in which there is no 'actual focus' in the grammar, but just a set of 'possible foci' from which discourse will choose the 'actual focus'. The implications of such an argumentation are strong: according to these theories, the 'actual focus' is set after the derivation has undergone Spell Out. Thus, for these theories, in the examples of the purported focus projection in (8) -repeated here as (22) for convenience- we don't have different grammatical sentences (understood

\footnotetext{
${ }^{13}$ See Zubizarreta (1998) for an analysis that proposes a different architecture of the language faculty and allows for this late insertion.
} 
as different derivations with the same word order that undergone Full Interpretation) but just one sentence whose F-Structure is ambiguous:

(22a) Jesus preached to the people of $[\text { Judea }]_{F}$

(22b) Jesus preached to the people [of Judea $]_{\mathrm{F}}$

(22c) Jesus preached to the [people of Judea $]_{F}$

(22d) Jesus preached to [the people of Judea $]_{\mathrm{F}}$

(22e) Jesus preached [to the people of Judea $]_{F}$

(22f) Jesus [preached to the people of Judea $]_{\mathrm{F}}$

$(22 \mathrm{~g})[\text { Jesus preached to the people of Judea }]_{\mathrm{F}}$

According to these theories, then, the 'actual focus' will not be a grammatical notion but a discursive one, and hence, inert to have any LF effect ${ }^{14}$. However, the LF effects of focus are widely attested in the literature (cf. Rooth (1985), Herburger (2000) among many others).

Finally, a big problem arises with the computation from Numeration to PF: recall that the assumption of these theories is that there is a legibility condition on derivations reclaiming that convergent derivations have nuclear stress on the focused XP. Otherwise the derivation crashes. The problem arises with the trigger of the operations that lead to the intended configuration. As explained before, in the literature some displacement operations such as Elordieta's (2001) 'scrambling' or Arregi's (2003) 'left and right dislocations' have been posited in order to account for the V-Focus adjacency as a byproduct of these movements. For these theories, the main problem is that according to basic assumptions in the minimalist program, displacement operations in syntax take place as an instance of feature-checking under a probe-goal relation. However, the movements that would provide

\footnotetext{
${ }^{14}$ It should also be inert to have the PF effects that it has, as we saw in section 4.1.
} 
the correct configurations for the postulates of NSR-based theories of F-Structure lack any other motivation than just providing that configuration. Furthermore, if we assume a Tmodel of the architecture of the grammar, a condition imposed on PF is unable to drive narrow syntactic operations, that is, there is no look ahead. And, unless specified further, the displacements that the NSR-based theories of F-Structure postulate are look ahead operations.

In a nutshell, the theoretical corollary of this section is the following one: if there is no $[+\mathrm{F}]$ feature and focus is just a configurational interpretation, then there should be no focally-induced displacements, and the nuclear stress should invariably fall on the most deeply embedded element. On the other hand, if there is a $[+\mathrm{F}]$ feature marking the focal $\mathrm{XP}$, then it is not the PF embedding configuration what marks it. Both ways, the NSR-based theories of F-Structure are incoherent.

\subsection{Summary of this section}

I have shown that the NSR-based theory of F-Structure is wrong both empirically and conceptually. The reasons I adduced are that some languages make use of categorically different pitch accents to convey broad and narrow foci; the conclusion being that the actual F-Structure is present at the phonological component. Hence, there can be no 'focus set' nor 'focus projection'. Furthermore, the strict alignment between the F-Structure and a phonological phrase boundary observed in many languages reinforces the impossibility of computationally ambiguous F-Structures. On the other hand, the lack of any accent to convey focus in some languages makes dubious the existence of the bare output condition (by definition, universal) that would require focused elements to bear nuclear stress. Likewise, I have discussed that the Focus-Verb adjacency observed in languages like 
Basque cannot be a byproduct of NSR and displacements. Finally, I have argued how theories that purport the assignment of one $[+\mathrm{F}]$ feature are stipulative and conceptually ill formed, and $[+\mathrm{F}]$ featureless theories are computationally inoperative.

In the next section I present a derivational approach to the F-Structure that overcomes the shortcomings of NSR-based theories. As will be shown, this system allows setting the F-Structure in the narrow syntax and, then, interface components are able to operate on it.

\section{5-A Derivational Approach to the F-Structure}

All the evidence given so far bears testimony to the need of a new theory of the FStructure. Thus in this section I propose a Derivational Theory of the F-Structure (DAFS, for short). The analysis is based on two main assumptions: that the $[+\mathrm{F}]$ feature is an optional formal feature that can be assigned to multiple tokens in the numeration (section 5.1), and that the F-Structure is created by set composition in Bare Phrase Structure (section 5.2).

\section{1-The $[+F]$ Feature as an optional formal feature}

According to Chomsky (1995b), a lexical entry is made up of three collections of features: Phonological Features, Semantic Features and Formal Features. Among the last ones, there is a subset of optional features that are added as the pertinent lexical item enters into the numeration. Within this framework, I would want to propose that the $[+\mathrm{F}]$ feature is one of these Optional Formal Features that can be interpreted both by PF and LF. In fact, the availability of this $[+\mathrm{F}]$ feature might not be optional for all the lexical items, and some lexical items might bear this $[+\mathrm{F}]$ feature lexically specified. These could be elements such 
as Wh-words, or the focus particles of languages like Somali (cf. Lecarme (1999)) or Tuki (cf. Biloa (1995)). In these elements, the $[+F]$ feature wouldn't be optional, but lexical (in case they are really always focal, which I doubt). The other side of this coin would be the question regarding whether there are lexical items that inherently are unfocussable, like the pronominal clitics of the romance languages for instance (I thank João Costa for the commentary). This is completely an empirical issue. I think that there might be some examples of metalinguistic contrastive focus even with expletives, but in any case, if this restriction is true, we have to posit it for any type of theory of the F-Structure, not only for the theory to be presented here. For the DAFS it would just be a ban on the $[+F]$ feature assignment for the relevant set of lexical items ${ }^{15}$. Furthermore, recall that in fact, if true, this impossibility of focalization of some elements might be another counterexample for the $N S R$-based theories since they allow for no nonfocal element within a focal projection. Thus, if clitics really are unfocussable, the appearance of a clitic in an out-of-the-blue sentence should trigger ungrammaticality (given that these theories don't allow for split FStructures). This, clearly, is not the case ( $c f$. section 5 for a brief analysis of split focus constructions in the current approach as well as Irurtzun (2005) for a more elaborate analysis).

\section{2-Derivation of the F-Structure}

Assuming that the $[+\mathrm{F}]$ feature is an optional formal feature, we can assume that this feature is assigned possibly, to multiple tokens of the lexicon in the numeration, and that

\footnotetext{
${ }^{15}$ The only lexical item that really seems to be unfocussable (not even metalinguistically) is pro. Again, if this generalization is correct, a ban on $[+\mathrm{F}]$ features should be added on these lexical items. However, on minimalist grounds, there is convincing evidence that pro might not even exist as such, its effects being better explained as instances of ellipsis of DPs ( $c f$. Duguine (2006) on this).
} 
the F-Structure will be constructed with the tokens bearing the $[+\mathrm{F}]$ feature. Note here that the postulation of a feature assignment in the numeration doesn't have to have any teleological flavor, and the assignment of the $[+\mathrm{F}]$ feature can be completely free (like, by assumption, the assignment of the feature [+Plural]). Hence, it would make little sense to pose the question of why some token of the numeration bears the $[+\mathrm{F}]$ feature while others don't. This is equal to ask why in the sentence (23) the subject is 'John' instead of 'Michael':

(23) John kissed Mary.

This, presumably, is a matter of lexical choice and, ultimately, of performance; and I won't address it here. Likewise for the $[+\mathrm{F}]$ feature assignment, I will just assume that this feature is assigned freely, and that the derivation unfolds as such creating the F-Structure (see below for an explanation of how this happens). Then, if the derivational outcome of the combination of the lexical items in a numeration results in an inappropriate F-Structure, this will be a matter of inappropriate discourse, but no grammatical violation will occur ${ }^{16}$.

Thus, at a descriptive level, the lexical tokens that will ultimately construct the FStructure will bear the $[+\mathrm{F}]$ feature, whereas other tokens won't. This amounts to say that there is no inherent property of some lexical items that makes them more 'focusable' than others, but just discursive reasons for their likeliness to be $[+\mathrm{F}]$ marked, since, in principle, all types of lexical items will be able to bear the $[+\mathrm{F}]$ feature. The fact that some of them are more usually marked as $[+\mathrm{F}]$ will depend completely on discourse-flow and information

\footnotetext{
${ }^{16}$ Quite the same for (23) if the proposition denoted by (23) happens to be contrary to fact. If this is the case and it is Michael that kissed Mary, the proposition expressed by (23) is just false, but no syntactic violation occurs and no malformation of the numeration is at stake.
} 
packaging, not on their grammatical category per $s e^{17}$. Thus, we will assume that all types of lexical items can bear the $[+\mathrm{F}]$ feature and that the likeliness of them to be $[+\mathrm{F}]$ is a completely independent issue (here again, I disagree with NSR-based theories of FStructure in that I assume that focusing the DP object is as economic as focusing any other DP).

Recall that, according to this proposal, for an element to bear the $[+\mathrm{F}]$ feature in the numeration does not mean that that lexical item will be the actual focus of the sentence but just that it will take part in the composition of the F-Structure, and the F-Structure is the outcome of the merger of $[+\mathrm{F}]$ featured items. As an illustration, given the appropriate question/answer pair in (24a-b), the only element in the Lexical Array of (24c) that will bear the $[+\mathrm{F}]$ feature in the answer in $(24 \mathrm{~b})$ is 'potatoes':

(24a) What does Ibon want?

(24b) He wants [potatoes] $\mathrm{F}$.

(24c) Lexical Array (simplified) for (24b): \{he, want, potatoes $\mathrm{F}\}$

In the same way, since no minimalist principle prohibits the insertion of various $[+\mathrm{F}]$ features, and given the dialogue in (25), my proposal is that in (25b) (an appropriate answer to the question in (25a)), we have two elements bearing the $[+\mathrm{F}]$ feature, 'potatoes' and the verb 'eats', as represented in $(25 \mathrm{c})$ :

(25a) What does Ibon do?

(25b) He [eats potatoes $]_{\mathrm{F}}$.

(25c) Lexical Array (simplified) for (25b): \{he, eat f $\left._{\text {potatoes }}\right\}$

\footnotetext{
${ }^{17}$ Hence, even if it is much more usual to add to our information stock expressions denoting individuals (of type e) than than quantifiers (of type $<<\mathrm{e}, \mathrm{t}>,<<\mathrm{e}, \mathrm{t}>, \mathrm{t}>>$ ), this will be a completely discourse-driven fact of information packaging: it is easy (and common) to ask for the identity of an individual, it is tougher to ask for a quantifier, and even tougher to ask, for instance, for a light verb. But there is no grammatical restriction preventing a light verb from being focused, this is a matter of 'informatics' (cf. Vallduví (1993))
} 
Given this multiplicity of $[+\mathrm{F}]$ featured tokens, my proposal would be that the FStructure is constructed as the derivation unfolds and structure is created. Hence, instead of a PF projection, it will be the outcome of phrase structure building in Bare Phrase Structure (cf. Chomsky (1995a)). For instance, given the configuration in (26a-b), where two $[+\mathrm{F}]$ marked elements are merging together, the syntactic object that will be created will be a set that contains only $[+F]$ featured lexical items:

(26a)

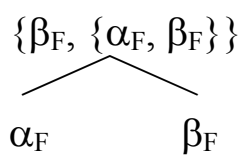

(26b)

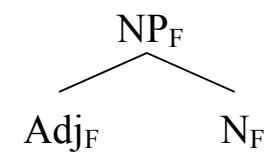

Thus, the newly created object will be read as focal by the interface components ${ }^{18}$. Likewise, when that object is merged with another element $\gamma$ that itself bears the $[+\mathrm{F}]$ feature:

(27a)

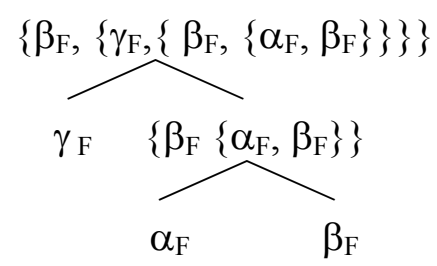

$(27 b)$

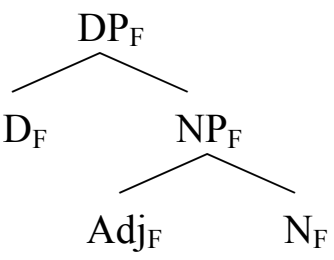

The newly created object will be a set containing no $[+\mathrm{F}]$ featureless lexical item.

On the other hand, if we have a $[+\mathrm{F}]$ featured element $\alpha$, and a $[+\mathrm{F}]$ featureless element $\beta$ undergoing merge, the newly created element won't be a set containing only $[+\mathrm{F}]$ featured material, and hence, the only chunk of structure to be read as focal will be the singleton $\{\alpha\}$ (crucially, whatever the label of the structure):

\footnotetext{
${ }^{18}$ For logical form, I am assuming that all the $[+\mathrm{F}]$ material is mapped into the scope of a restricted quantification over events (where the background material creates the restriction), as proposed in Herburger (2000). See Irurtzun (2006) on this.
} 
(28a)

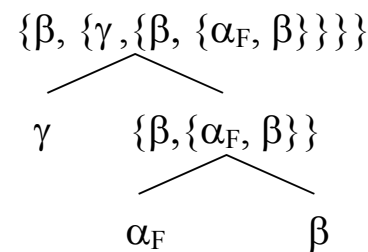

$(28 b)$

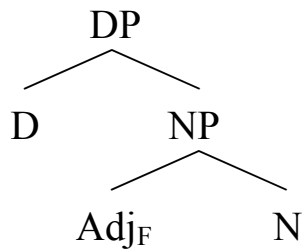

Thus, with the adoption of this derivational theory, there will be no focus projection as such, but just F-Structure composition. This allows us to account for the variability of FStructure possibilities without having to postulate optional operations of focus projection; the optionality comes for free built up in lexical choice (a virtual conceptual necessity).

In order to show how the system works in longer phrases, let us say that we have the simplified numeration in $(29)^{19}$. When the $[+F]$ object is merged with the $[+F]$ featureless verb the object won't be able to 'project' it further up, since its sister node (the verb), doesn't bear itself the $[+F]$ feature. Such a configuration would end up in a sentence like (29b) with the direct object as its focus:

(29a) Lexical Array: $\left\{\{\right.$ Mary $\},\left\{\operatorname{John}_{\mathrm{F}}\right\},\{$ kiss $\left.\},\{\mathrm{v}\}\right\}$

(29b) Mary kisses [John $]_{\mathrm{F}}$

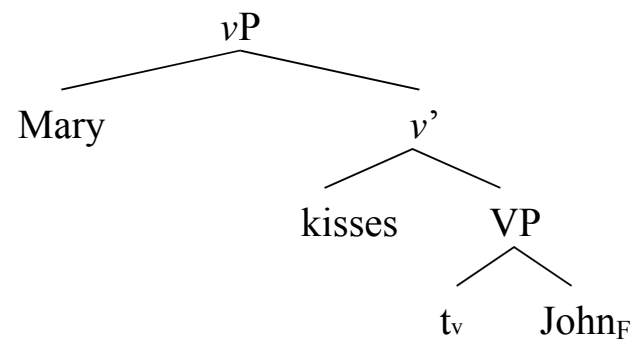

Right in the same way, if we have the numeration in (30a), when the object bearing a $[+\mathrm{F}]$ feature is merged with the verb that itself bears the $[+\mathrm{F}]$ feature, the VP created will contain only $[+\mathrm{F}]$ featured lexical items ${ }^{20}$. Hence, since there is no other $[+\mathrm{F}]$ featured item on the numeration of (30a), the F-Structure will be a VP, as in sentence (30b):

\footnotetext{
${ }^{19}$ I will simplify the presentations abstracting away from Tense and higher projections.

${ }^{20} \mathrm{I}$ will assume here for the ease of exposition that the light verb itself also bears the $[+\mathrm{F}]$ feature.
} 
(30a) Lexical Array: $\left\{\{\right.$ Mary $\left.\},\left\{\operatorname{John}_{\mathrm{F}}\right\},\left\{\operatorname{kiss}_{\mathrm{F}}\right\},\left\{\mathrm{v}_{\mathrm{F}}\right\}\right\}$

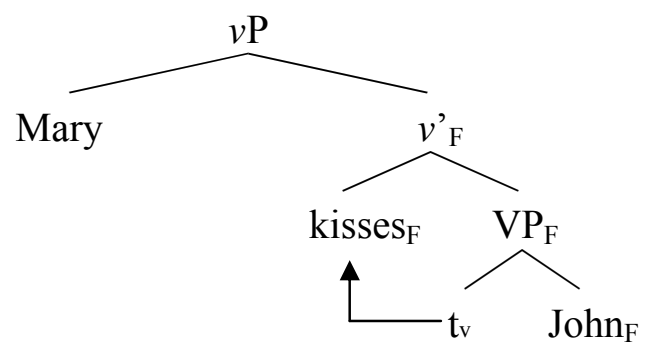

(30b) Mary [kisses John]

Instead, if we have the numeration under (31a), when the object and the verb are merged, a new syntactic/set theoretic object is created out of elements that bear the $[+\mathrm{F}]$ feature. Once this object is merged with the light verb and the new element with the subject that itself bears the $[+\mathrm{F}]$ feature, $v \mathrm{P}$ focus is obtained:

(31a) Lexical Array: $\left\{\left\{\operatorname{Mary}_{\mathrm{F}}\right\},\left\{\operatorname{John}_{\mathrm{F}}\right\},\left\{\operatorname{kiss}_{\mathrm{F}}\right\},\left\{\mathrm{v}_{\mathrm{F}}\right\}\right\}$

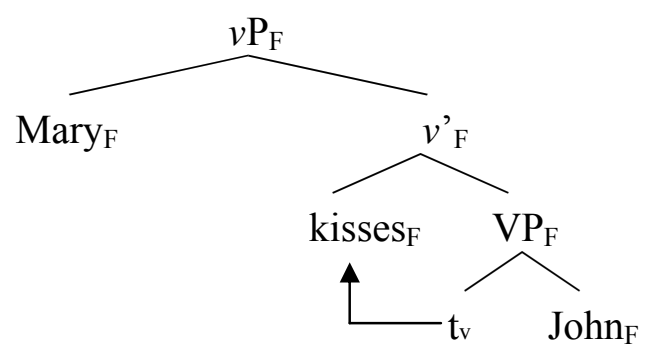

(31b) [Mary kisses John]F

Thus, the node with the highest $[+\mathrm{F}]$ feature will demarcate the F-Structure of the sentence, i. e., a XP will be interpreted as focal if all the lexical items that build up that XP are $[+\mathrm{F}]$ marked.

Thus, according to this proposal (and contrary to the idea of 'focus set' of the NSRbased theories), in (32-38) we won't have a single derivation with an ambiguous FStructure (cf. 8a-g) but seven different sentences each one with a different focus. The 
question is that all of them end up with the same linearization: \#Jesus preached`to^the^people^of Judea\#.

(32) Jesus preached to the people of [Judea $]_{\mathrm{F}}$

(33) Jesus preached to the people [of Judea $]_{\mathrm{F}}$

(34) Jesus preached to the [people of Judea]F

(35) Jesus preached to [the people of Judea $]_{\mathrm{F}}$

(36) Jesus preached [to the people of Judea]

(37) Jesus [preached to the people of Judea]

(38) [Jesus preached to the people of Judea $]_{\mathrm{F}}$

In order to explain the fact that in all the sentences in (32-38), the PF component assigns the nuclear stress to "Judea" it will be sufficient to make the Cinquean-like NSR focus-sensitive:

(39) Assign nuclear stress to the most embedded element within the F-Structure.

That is, having the F-Structure set in narrow syntax, interface components can read it as a structural description for the PF and LF rules of accentuation, phrasing, association with operators etc. Thus, this new NSR will predict correctly and without any further stipulation the nuclear stress placement in different positions, given that the differences in the F-Structures are already set in narrow syntax. Thus, in (40-44), like in (32-38) we will have different sentences (i.e., different derivations constructed from different numerations). Applying the focus-sensitive NSR to each of the derivations, we predict the actual placement of nuclear stress:

(40) John boiled [water $]_{\mathrm{F}}$

(41) John [boiled water $]_{F}$

(42) [John boiled water $]_{F}$ 
(43) $[\text { John }]_{\mathrm{F}}$ boiled water

(44) John [boiled $]_{\mathrm{F}}$ water

Thus, a natural conclusion of this proposal is that focusing the subject is not computationally more complex than focusing the object, i.e. it doesn't involve more operations (contrary to theories like Reinhart $(1995,2006)$, that, as we saw, postulate a default application of the NSR to focus on the object, but a default application of the NSR, a deaccentuation operation of the object, and a marked stress rule to mark focus on the subject). Likewise for the verb or any other element.

Furthermore, this derivational approach will be able to account for the availability of sentence-whole focus with nuclear stress on the subject of unergatives and unaccussative predicates (the so-called 'Schmerling examples' that are highly problematic for the NSRbased theories (cf. Schmerling (1976), Rochemont (1998))). These are examples like (45b), along with (45c), a proper answer to (45a):

(45a) What happened?

(45b) $[\text { Reagan died }]_{\mathrm{F}}$

$(45 \mathrm{c})[\text { Reagan died }]_{\mathrm{F}}$

The puzzle is that in (45b) nuclear stress falls on the subject, but the whole sentence is focused (something that, as we saw before (cf. section 3), NSR-based theories of FStructure predict not to be possible).

Within the DAFS, the explanation would be along these lines: following mainstream assumptions, if the subjects of these constructions are first merged in object position, the derivation of the sentence-whole focus is straightforward: if both the object and the verb bear the $[+\mathrm{F}]$ feature, when merged together a new set of $[+\mathrm{F}]$ featured elements will be created; then the A-movement applies. Now, the fact that in some cases like (45b) it is the 
subject, rather than the lower verb that gets the nuclear stress should be analyzed as some sort of exclamative stress shift since, on the one hand, it is not mandatory, as the grammatical (45c) shows, and on the other hand, it needs a highly marked surprise context to be felicitous.

Needless to say, another welcome result of the adoption of the DAFS is that this system will also derive the semantic type of the F-Structure. It will just be a product of the standard bottom-up semantic composition. Whichever lexical items enter into the numeration with the $[+\mathrm{F}]$ feature, the type of the F-Structure will be the outcome of their composition:

(46) $\left[\left[[\text { The }]_{(F)}[\mathrm{man}]_{(F)}\right]_{(F)}\left[[\text { took }]_{(F)}\left[[\text { the }]_{(F)}[\text { book }]_{(F)}\right]_{(F)}\right]_{(F)}\right]_{(F)}$

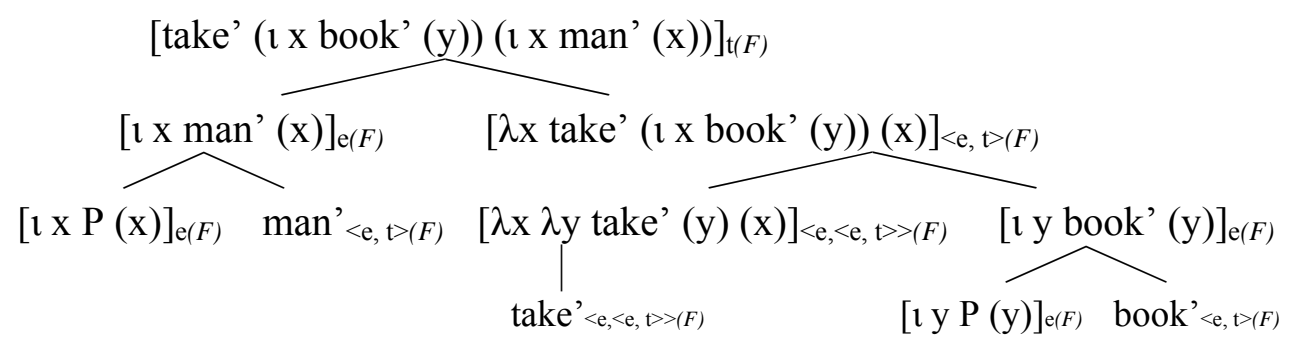

This allows the F-Structure to have a determinate size in logical form, and hence, focus can have a determinate semantic interpretation.

Summing up this section, I have proposed that the $[+\mathrm{F}]$ feature is an optional formal feature that can be assigned to multiple tokens of the numeration. Then, the F-Structure is constructed (instead of 'projected') bottom-up and in a fully derivational way given Bare Phrase Structure (cf. Chomsky (1995a)), and the F-Structure is set in narrow syntax and before Spell Out (contra the NSR-based theories that set the F-Structure late in PF). This allows foci to have PF and logical form interpretations. 


\section{6-A Consequence of the Derivational Approach to the Focus Structure}

Finally, I want to present a welcome consequence of adopting the derivational approach to the focus structure just presented ${ }^{21}$.

Note that, in principle, a potential puzzle arises when no merge/bottom-up composition can be done with two elements that bear themselves the $[+\mathrm{F}]$ feature in the numeration. These are cases like the one in (47), where the subject and the object, bearing each one the $[+\mathrm{F}]$ feature, are isolated from each other. There is no node that dominates at the same time both $[+\mathrm{F}]$ marked constituents and that is solely constituted of $[+\mathrm{F}]$ marked material (in other words, they are not sisters). These will be constructions like (47b), derived from lexical items like those in (47):

(47): Lexical Array (simplified): $\left\{\{\text { Mary }\}_{\mathrm{F}},\{\text { John }\}_{\mathrm{F}},\{\right.$ kiss $\left.\},\{\mathrm{v}\}\right\}$

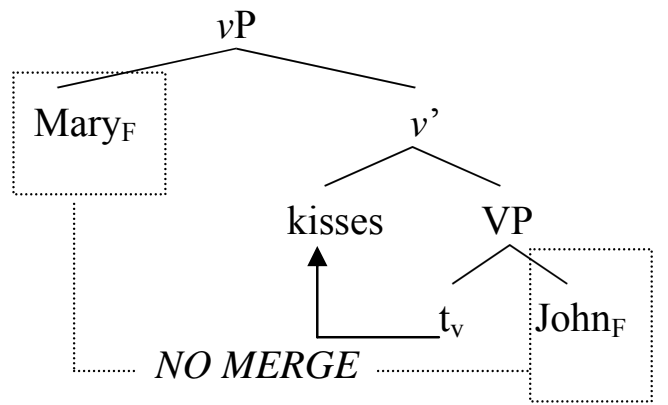

(47b) $[\text { Mary }]_{\mathrm{F}}$ kisses $[\mathrm{John}]_{\mathrm{F}}$

Recall that for the NSR-based theories these constructions (answers to multiple Wh questions) are unapproachable, since they conceive only one nuclear stress and its projection of focus. On the other hand, with the adoption of the derivational theory presented here, these constructions will have a natural explanation as derivationally split FStructures derived from isolated $[+\mathrm{F}]$ marked lexical items. And, furthermore, this is precisely the kind of structure that we need for interpretation: assuming a semantics of

${ }^{21}$ I will just mention the main point here, see Irurtzun (2005) for a more specific account of these constructions. 
multiple Wh questions à la Chomsky (1973) or Higginbotham \& May (1981), at LF the two Wh operators of a multiple Wh question create, by absorption, a complex polyadic operator that binds pairs of variables (precisely, the variables that each of the isolated foci of (47b) stand for):

(48) Who kissed whom?

LF: [WH $x$, WHy: person(x) \& person $(y)] x$ kisses $y$

Furthermore, in PF as well, this analysis predicts as many nuclear stress assignments as $[+\mathrm{F}]$ featured isolates. And in fact, this is the intonational pattern of many languages that show a pitch accent assignment to each of the elements that answers partially the question (cf. the data in Jackendoff (1972)) for English, Büring (1999) for German, Godjevać (2000) for Serbo-Croatian, or Elordieta (2001) for Basque among many others, and Irurtzun (2005) for a full account of the derivation of split foci like these).

To finish, the implications of this theory are clear: it should be grammatically possible to have various items marked as $[+\mathrm{F}]$ in the derivation, creating a multiply split FStructure. In principle, I see no problem with this prediction. The oddity of these constructions should be regarded as a discursive or processing factor. Quite the same that happens with Wh-words: the fact that we don't usually make questions with, for instance, 8 Wh-words shouldn't be treated as a grammatical impossibility but rather a processing restriction (and/or lack of discursive interest). Therefore, likewise for the answer of such a question.

Thus, the issue of the isolability of $[+\mathrm{F}]$ marked material constitutes a welcome prediction of the derivational approach presented here, rather than a shortcoming.

\section{7-Summing up}


In this paper, I have argued that mainstream, NSR-based theories of the F-Structure cannot be maintained. The empirical evidence and conceptual arguments presented in section 4 show that, computationally, focus is not interpreted depending on where the nuclear stress falls, but quite the opposite: nuclear stress is but a way of representing in PF a necessarily syntactically built up F-Structure. Thus, the arguments on the basis of a NSRbased theory of the F-Structure have been shown to be circular. Then, I presented a derivational construal of the F-Structure by considering the $[+\mathrm{F}]$ feature as an optional formal feature and allowing its assignment to various items of the numeration. The FStructure is constructed as in Bare Phrase Structure when two [+F] featured elements are merged together, since the set theoretic object that results from their merger will be an element that contains just $[+\mathrm{F}]$ featured lexical items. F-Structure is, then, strictly compositional. As a consequence, this setting of the F-Structure in narrow syntax overcomes the core circularity problems of NSR-based theories of the F-Structure (as I argued in section 4.3). Furthermore, having the F-Structure already set in the narrow syntax allows the F-Structure to be interpreted at both interface components. Thus, the F-Structure can be assigned nuclear stress and likewise, a determinate phonological phrasing at PF, and it can have the semantic interpretive effects that it has at logical form. In these aspects as well, the derivational construal of the F-Structure presented in this article proves to be superior in many respects to previous analyses based on the NSR that postulated invasive look ahead effects of interface representations to drive operations in narrow syntax. 


\section{8-References}

Arregi, K., 2003, Focus on Basque Movements, PhD. Diss: MIT.

Baltazani, M., 2002, Quantifier scope and the role of intonation in Greek, Ph. Diss: UCLA. Bickerton, D., 1993, "Subject Focus and Pronouns", in F. Byrne \& D. Winford (eds.), Focus and Grammatical Relations in Creole Languages, Amsterdam \& Philadelphia: John Benjamins, pp. 189-212.

Biloa, E., 1995, Functional Categories and the Syntax of Focus in Tuki, Müenchen \& Newcastle: Lincom Europa.

Büring, D., 1999, "Topic”, in P. Bosch \& R. van der Sandt (eds.), Focus: Linguistic, Cognitive, and Computational Perspectives, Cambridge (UK): Cambridge University Press, 142-165.

Chomsky, N., 1973, "Conditions on Transformations", in S. Anderson \& P. Kiparsky (eds.), A Festschrift for Morris Halle: Holt Rinehart \& Winston. [Reprinted in Chomsky, 1977, Essays on Form \& Interpretation, New York: Elsevier North Holland, pp.81-162].

Chomsky, N., 1995a, "Bare Phrase Structure", in G. Webelhuth (ed.), Government and Binding Theory and The Minimalist Program, Oxford, Blackwell, pp. 383-439.

Chomsky, N., 1995b, The Minimalist Program, Cambridge (MA): MIT Press.

Cinque, G., 1993, “A Null Theory of Phrase and Compound Stress”, in Linguistic Inquiry 24, pp. 239-298.

D'Imperio, M., 2002, "Italian Intonation: An overview and some questions", in Probus 14, pp. 37-69.

Derbyshire, D. C., 1985, Hyxkariana and Linguistic Typology, Dallas (TX): SIL \& University of Texas at Arlington.

Duguine, M., 2006, "Silent arguments without pro: the case of Basque", manuscript: EHUU. Basque Country \& U. Naoned-Nantes.

Elordieta, A., 2001, Verb Movement and Constituent Permutation in Basque, PhD. Diss., HIL/Leiden University, LOT Dissertation Series.

Elordieta, G., 2006, “Constraints on Intonational Prominence of Focalized Constituents”, in Ch. Lee, M. Gordon \& D. Büring (eds.), Topic and Focus: Intonation and Meaning, Dordrecht: Kluwer Academic Press. 
Féry, C., 2001, "Focus and Phrasing in French", in C. Féry \& W. Sternfeld (eds.), Audiatur Vox Sapientiae. A Festschift for Arnim von Stechow, Berlin: Akademie-Verlag, pp. 153-181.

Frota, S., 2000, Prosody and Focus in European Portuguese, New York: Garland.

Godjevać, S., 2000, Intonation, Word Order, And Focus Projection in Serbo-Croatian, Ph. Diss: The Ohio State University.

Halle, M. and J. R. Vergnaud, 1987, An Essay on Stress, Cambridge (MA): MIT Press.

Hayes, B. and A. Lahiri, 1991, "Bengali Intonational Phonology", in Natural Language and Linguistic Theory 9, pp. 47-96.

Herburger, E., 2000, What Counts: Focus and Quantification, Cambridge (Mass.): MIT Press.

Higginbotham, J. and R. May, 1981, "Questions, Quantifiers and Crossing", in The Linguistic Review 1, pp. 41-80.

Hualde, J.I. and J. Ortiz de Urbina, 2003, A Grammar of Basque, Berlin: Mouton de Gruyter.

Irurtzun, A., 2003, "The Intonational Phonology of Errenteria Basque", paper presented at the $1^{\text {st }}$ Phonetics and Phonology in Iberia Conference, Lisbon.

Irurtzun, A., 2005, "Structure and Derivation of Split Focalization", in C. Umbach and C. von Heusinger (eds.), Proceedings of the ESSLLI Workshop on Discourse Domains \& Information Structure: Heriot Watt University, pp. 21-33.

Irurtzun, A., 2006, "Focus \& Clause Structuration in the Minimalist Program", in C. Boeckx (ed.), Minimalist Essays, Amsterdam: John Benjamins, pp. 68-96.

Ishihara, S., 2000, "Stress, Focus, and Scrambling in Japanese", in MIT Working Papers in Linguistics 39; A View from Building E-39, pp. 142-175.

Jackendoff, R., 1972, Semantic Interpretation in Generative Grammar, Cambridge (Mass.): MIT Press.

Jun, S-A., 1993, The Phonetics and Phonology of Korean Prosody, PhD. Diss: Ohio State University.

Kannerva, J. M., 1990, "Focusing on Phonological Phrases in Chicheŵa", in S. Inkelas \& D. Zec (eds.), The Phonology-Syntax Connection, Chicago \& London: University of Chicago Press, pp. 145-162. 
King, T. H., 1995, Configuring Topic and Focus in Russian, Stanford (CA): CSLI.

Kiss, K. É., 1995, “Introduction”, in K. É. Kiss (ed.), Discourse Configurational Languages, New York (NY): Oxford University Press, pp. 3-27.

Ladd, D. R., 1996, Intonational Phonology, Cambridge: Cambridge University Press.

Laka, I. and J. Uriagereka, 1987, "Barriers for Basque and Vice-Versa", in J. McDonough and B. Phunkett (eds.), Proceedings of NELS 17, Amherst MA: GLSA, pp. 394-408.

Lecarme, J., 1999, "Focus in Somali", in Rebuschi \& Tuller (eds.), The Grammar of Focus, Amsterdam: John Benjamins, pp. 275-310.

Liberman, M. Y., 1975, The Intonational System of English, PhD. Diss: MIT.

Neeleman, A., and T. Reinhart, 1998, "Scrambling and the PF Interface", in M. Butt \& W. Geuder (eds.), The Projection of Arguments; Lexical and Compositional Factors, Stanford: CSLI Publications, pp. 309-353.

Ortiz de Urbina, J. 1989, Parameters in the Grammar of Basque, Dordrecht: Foris.

Ortiz de Urbina, J. 1995, "Residual Verb First and Verb Second in Basque", in K. É. Kiss (ed.), Discourse Configurational Languages, New York (NY): Oxford University Press, pp. 99-121.

Pierrehumbert, J., 1980, The Phonology and Phonetics of English Intonation, PhD. Diss: MIT.

Pierrehumbert, J. and M. Beckman, 1988, Japanese Tone Structure, Cambridge (MA): MIT Press.

Pierrehumbert, J. B. and J. Hirschberg, 1990, "The meaning of intonational contours in the interpretation of discourse", in P. Cohen, J. Morgan and M. Pollack (eds.), Intentions in Communication, Cambridge (MA): MIT Press, pp. 271-311.

Reinhart, T., 1995, “Interface Strategies”, OTS Working Papers in Linguistic, TL-95-002, Utrecht: Utrecht University.

Reinhart, T., 2006, Interface Strategies: Optimal and Costly Computations, Cambridge (MA): MIT Press.

Rialland, A. and S. Robert, 2001, “The Intonational System of Wolof”, in Linguistics 39-5, pp. 893-939. 
Rochemont, M., 1998, "Phonological Focus and Structural Focus", in P. Culicover \& L. McNally (eds.), Syntax and Semantics: The Limits of Syntax, San Diego (CA): Academic Press, pp. 337-363.

Rooth, M., 1985, Association with Focus, PhD. Diss: UMass.

Sandalo, F. and H. Truckenbrodt, 2002, "Some Notes on Phonological Phrasing in Brazilian Portuguese", in A. Csirmaz et alii (eds.), Phonological Answers (and their Corresponding Questions): MIT Working Papers in Linguistics 42, pp. 285-310.

Schmerling, S., 1976, Aspects of English Sentence Stress, Autstin (TX): Austin University Press.

Schwarzschild, R., 1999, "GIVENness, AvoidF, and other constraints on the placement of accent", in Natural Language Semantics 7, pp. 141-177.

Selkirk, E., 1995, “Sentence Prosody: Intonation, Stress, and Phrasing”, in J. A. Goldsmith (ed.), The Handbook of Phonological Theory, Oxford: Blackwell, pp. 550-569.

Selkirk, E., 2000, “The Interaction of Constraints on Prosodic Phrasing”, in M. Horne (ed.), Prosody: Theory and Experiment: Studies Presented to Gösta Bruce, Dordrecht: Kluwer, pp. 231-262.

Selkirk, E., 2002, "Contrastive FOCUS vs. presentational focus: Prosodic Evidence from Right Node Raising in English", in B. Bel and I. Marlin (eds), Speech Prosody 2002: Proceedings of the 1st International Conference on Speech Prosody, Aix-enProvence, pp. 643-646.

Selkirk, E., 2006, "Bengali Intonation Revisited: An optimality theoretic analysis in which FOCUS stress prominence drives FOCUS phrasing”, in Ch. Lee, M. Gordon \& D. Büring (eds.), Topic and Focus: Intonation and Meaning, Dordrecht: Kluwer Academic Press, pp. 215-244.

Szendröi, K., 2001, Focus and the Syntax-Phonology Interface, PhD. Diss: UCL.

Truckenbrodt, H., 1995, Phonological Phrases: Their Relation to Syntax, Focus, and Prominence, PhD. Diss: MIT.

Truckenbrodt, H., 1999 "On the relation between syntactic phrases and phonological phrases", in Linguistic Inquiry 90-2, pp. 219-255.

Vallduví, E., 1993, The Informational Component, PhD. Diss: UPenn.

Zubizarreta, M. L., 1998, Prosody, Focus and Word Order, Cambridge (MA): MIT Press. 
Zubizarreta, M. L. and J. R. Vergnaud, 2000, "Phrasal Stress and Syntax", in M. Van Oostendorp and E. Anagnastopoulou (eds.), Progress in Grammar: Articles at the 20th Anniversary of the Comparison of Grammatical Models Group in Tilburg, electronic publication

URL:

http://www.roquade.nl/meertens/progressingrammar/index.html 